\title{
Thyrotrophin augmentation after commencing thyroxine replacement in primary hypothyroidism
}

\author{
R.R. Ghose and H.P. Upadhyay \\ Singleton Hospital, Sketty, Swansea SA2 8QA, UK.
}

\begin{abstract}
Summary: Prospective measurements of serum thyrotrophin and thyroxine concentrations were made in six patients with primary hypothyroidism treated consecutively with an incremental regimen of oral thyroxine. A fall in thyrotrophin occurred over several months, accompanied by a concurrent slow rise in serum thyroxine. Those patients with the highest initial values for thyrotrophin showed the typical curvilinear decline in thyrotrophin, whereas the remaining patients disclosed a transient rise in thyrotrophin for the first 3 months. This paradoxical rise was not associated with depression of cardiac output or glomerular filtration rate.

The significance of thyrotrophin augmentation is uncertain, but it may be more common than generally appreciated. It did not occur in those patients with the most severe degrees of thyroid deficiency. Thyroxine exerts a dual action, and augmentation of thyrotrophin may reflect a dominant effect of increased protein synthesis, in contrast to negative feedback inhibition which suppresses thyrotrophin. These opposing actions are in competition at different dose levels of thyroxine, and may contribute not only to augmentation or suppression of thyrotrophin, but also to the curvi-linear pattern of fall. Such variations impair the utility of thyrotrophin as an index of euthyroidism.
\end{abstract}

Introduction

Diminished levels of serum thyroxine $\left(\mathrm{T}_{4}\right)$ and $3,5,3^{1-}$ tri-iodothyronine $\left(\mathrm{T}_{3}\right)$ concentrations in primary hypothyroidism are associated with high levels of thyroid-stimulating hormone (TSH), because pituitary thyrotrope secretion of TSH is governed by negative feedback regulation. The complex processes involved are not fully resolved (Scanlon et al., 1978). Administration of oral thyroxine to untreated patients with primary hypothyroidism promptly initiates a curvi-linear fall in TSH which is roughly proportional to the dose (Cotton et al., 1971). Occasionally, however, the fall in TSH may be interrupted by a paradoxical rise, which has been described in sporadic case reports (Wartofsky et al., 1976; Hood et al., 1976) and in experimental studies (Garcia et al., 1976). It is possible that this rise is more common than generally realized, as revealed by detailed studies of TSH progression (Aizawa et al., 1978). Accordingly, a prospective study of TSH responsiveness to oral thyroxine was undertaken in six patients with primary hypothyroidism.

Correspondence: R.R. Ghose, F.R.C.P. Accepted: 31 July 1985
Patients and methods

Six consecutive patients with characteristic signs, symptoms and laboratory features of primary hypothyroidism were included in the study. Goitre was not present, and thyroid surgery had not previously been performed. All patients showed high titres of thyroid antibodies. There was no clinical evidence of cardiac enlargement or pericardial effusion, and no other endocrine disorder was manifest. There were 5 females and 1 male, with ages ranging from 16 to 65 , mean 44 years.

Starting dose of oral thyroxine was $25 \mu \mathrm{g} /$ day which was continued for 4 weeks, after which there was an increment by $25 \mu \mathrm{g} /$ day for a further 4 weeks, and this incremental regime was continued until serum TSH eventually returned to the normal range (below $5 \mathrm{IU} /$ $\mathrm{ml}$ ). The dosage schedule was different in Case 1 when starting dose, and increments, were $50 \mu \mathrm{g} / \mathrm{day}$.

Serum $\mathrm{T}_{4}$ and TSH concentrations were measured by radio-immunoassay, using Corning's immophase kit. Cardiac output was estimated by the technique of trans-thoracic cardiac impedance (Kubicek et al., 1966). Glomerular filtration rate (GFR) was measured by single-shot administration of ${ }^{51} \mathrm{Cr}$ EDTA (Morgan et al., 1977). 


\section{Results}

Figures 1, 2, 3, 4, 5 and 6 represent Cases 1, 2, 3, 4, 5 and 6 respectively. The effect of incremental thyroxine dosage on sequential basal serum TSH concentration and serum $T_{4}$ concentration is displayed, and concomitant measurements of cardiac output and GFR are included in Cases 4, 5 and 6.

In Cases 1, 2 and 3 the effect on TSH with the lowest dose of thyroxine was notable as the rise in serum $T_{4}$ was slight and well below the normal range for serum $\mathrm{T}_{4}$. A dramatic fall in TSH was observed in these patients initially, but TSH entered the normal range in the third month in Cases 1 and 2, and in the fifth month in Case 3. Serum $\mathrm{T}_{4}$ entered the normal range at 2.5 months in Cases 1 and 2, and at 2 months in Case 3.

A paradoxical rise in TSH is present in Cases 4, 5 and 6 . These values reached a peak and then declined spontaneously in spite of a continued incremental dose schedule of thyroxine. Throughout these changes in TSH there was evident rising levels of serum $T_{4}$, cardiac output and GFR. Serum TSH returned to the normal range at 7 months in Case 5 , and 5 months in Case 6. Continued observations were not possible in Case 4 because she left the area. Serum $T_{4}$ reached the normal range in the third month in Cases 4 and 5, and the second month in Case 6.
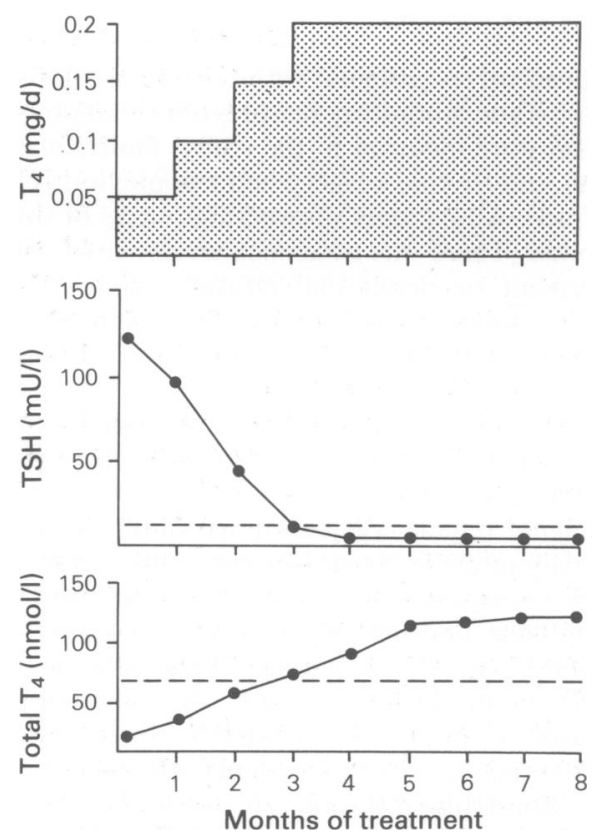

Figure 1 TSH fell to the normal range by the 3rd month
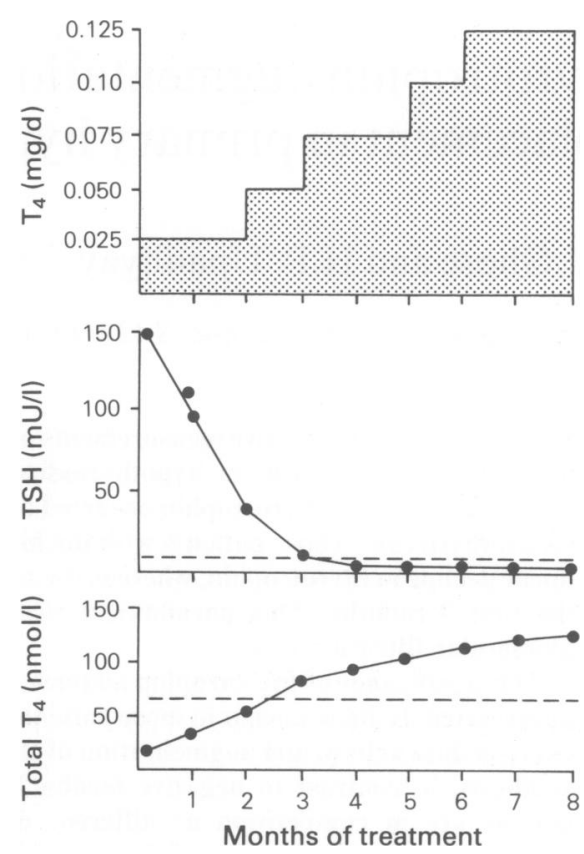

Figure 2 TSH fell to the normal range by the 3 rd mont
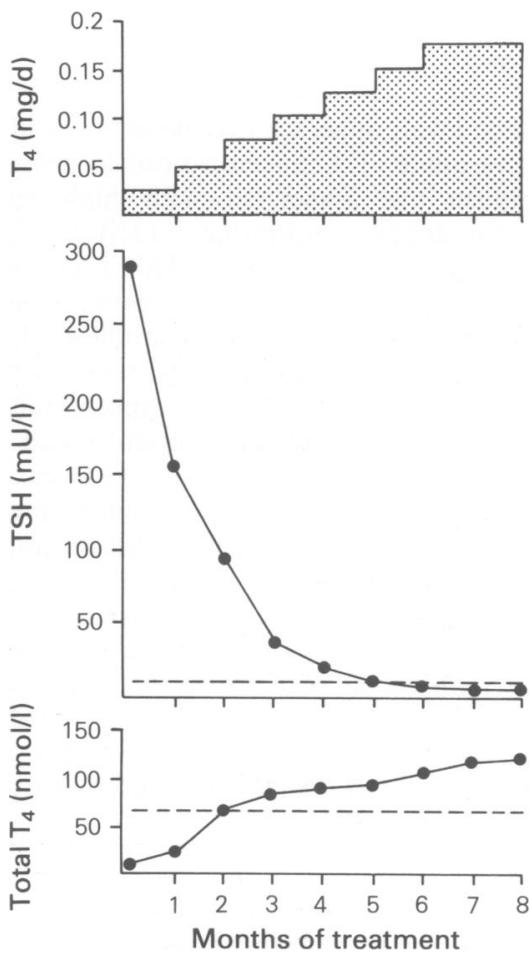

Figure 3 TSH fell to the normal range by the 5th montlo 

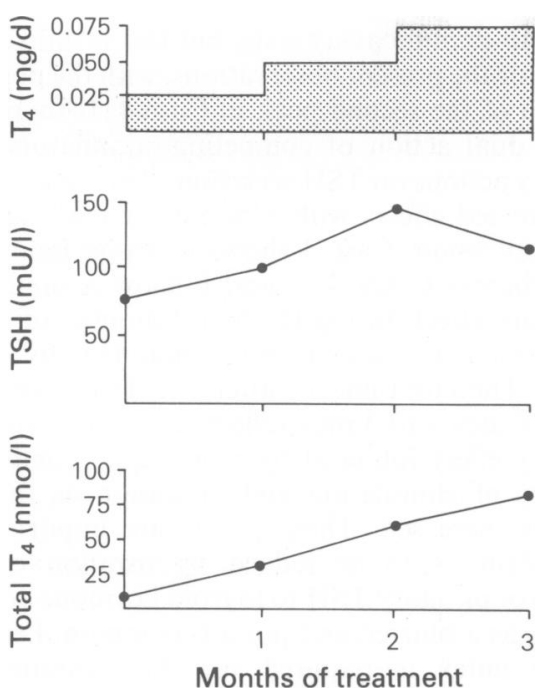

Figure 4 TSH showed a paradoxical rise and was still abnormal by the 3rd month
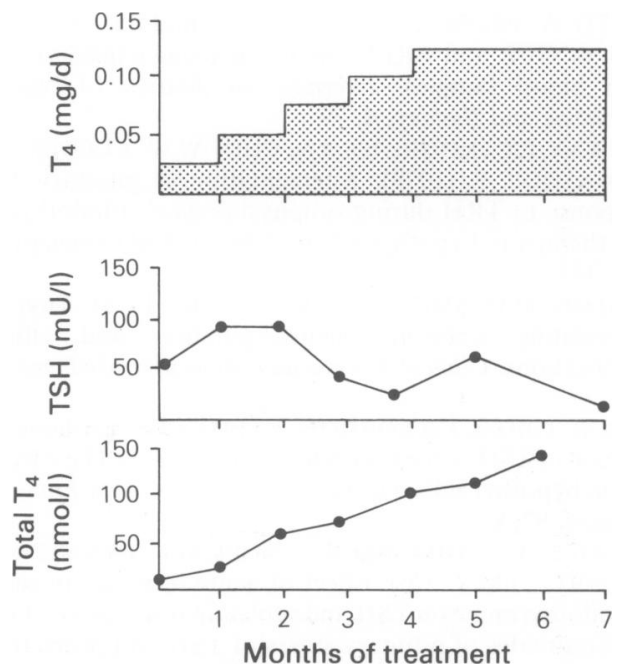

Figure 5 TSH showed a double peak and returned to the normal range by the 7 th month
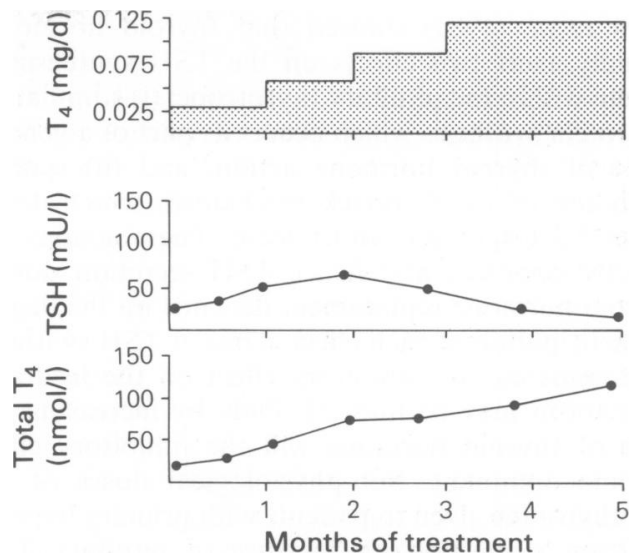

Figure 6 TSH showed a paradoxical rise but returned to the normal range by the 5 th month

\section{Discussion}

Sequential measurements of serum TSH are routinely made during thyroxine replacement therapy for primary hypothyroidism in order to define the euthyroid state, which is judged to coincide with the point in time at which serum TSH returns to the normal range. A fall in TSH values is generally anticipated, but it is clear from the present study that an initial rise in TSH is not uncommon, and should not be misinterpreted as a further manifestation of hypothyroidism. Effective gastro-intestinal absorption of thyroxine was present in all patients, as shown by a progressive rise in serum $\mathrm{T}_{4}$ during incremental dosage. Highly sensitive pituitary thyrotrope responsiveness to lowdose thyroxine occurred at subnormal concentrations of serum $T_{4}$. Yet divergent responses were demonstrated, with TSH falling in three patients and rising in three patients. That the pituitary thyrotrope may be directly affected by thyroxine even when serum $T_{4}$ remains abnormally low has been previously documented (Erfurth \& Hedner, 1982). Fifty per cent of intra-pituitary $T_{4}$ is converted to $T_{3}$ by binding to specific nuclear receptors in which new protein synthesis takes place (Larsen et al., 1979).

In the three patients who displayed augmentation of TSH after commencing thyroxine there were concurrent rises in cardiac output and GFR, along with a simultaneous rise in serum $\mathrm{T}_{4}$, indicating appropriate biological responsiveness of peripheral tissues in the face of inappropriate pituitary thyrotrope activity. D'Angela et al. (1976) first observed a 'rebound' phenomenon of TSH secretion in chronically hypothyroid rats, noting an increase in TSH biosynthesis with small doses of thyroxine in contrast to large doses which decreased TSH biosynthesis. Further studies by 
Spira et al. (1981) showed that thyroid hormones actually exert two effects on the TSH synthesizing system within the pituitary thyrotrope: (i) stimulation of protein synthesis which occurs as part of a general effect of thyroid hormone action, and (ii) specific inhibition of the feedback mechanism which determines TSH synthesis and release. These actions are directly opposed, and hence TSH secretion during thyroid hormone replacement depends on the degree of participation of each effect. Thus, if TSH synthesis predominates, the inhibitory effect on the feedback mechanism may be masked. Only by increasing the dose of thyroid hormone will the inhibitory effect become dominant. Sub-physiological doses of triiodothyronine given to patients with primary hypothyroidism stimulated an increase in pituitary TSH reserve following thyrotrophin releasing hormone provocation (Ridgway et al., 1979). This augmented TSH response occurred early in the course of subphysiological tri-iodothyronine treatment, when $T_{3}$ absorption and peripheral responsiveness was normal.

In this group of patients basal TSH displayed a consistent serial trend over several months of observation, providing a valid reflection of pituitary thyrotrope responsiveness. It is well known that between-batch variability, up to $10 \%$, can occur with

\section{References}

AIZAWA, T., KOIZUMI, Y., TAWATA, M., NAGATA, H., IZUMIYAMA, T. \& YOSHIZAWA, K. (1978). Difference in pituitary thyroid feedback regulation in hypothyroid patients, depending on the severity of hypothyroidism. Journal of Clinical Endocrinology and Metabolism, 47, 560.

COTTON, G.E., GORMAN, C.A. \& MAYBERRY, W.E. (1971). Suppression of thyrotropin (h-TSH) in sera of patients with myxedema of varying etiology treated with thyroid hormones. New England Journal of Medicine, 285, 529.

D'ANGELA, S.A., PAUL, D.H., WALL, N.R. \& LOMBARDI, D.M. (1976). Pituitary thyrotropin (TSH) rebound phenomenon and kinetics of secretion in the goitrous rat; differential effects of thyroxine on synthesis and release of TSH. Endocrinology, 99, 935.

ERFURTH, E.M. \& HEDNER, P. (1982). Importance of thyroxine in suppressing secretion of thyroid-stimulating hormone after thyroidectomy. British Medical Journal, 284, 941 .

GARCIA, M.D., ESCOBAR DEL REY, F. \& MORREALE DE ESCOBAR, G. (1976). Thyrotropin-releasing hormone and thyroid hormone interactions on thyrotropin secretion in the rat: lack of inhibiting effects of small doses of triiodo-Lthyronine in the hypothyroid rat. Endocrinology, 98, 203.

HOOD, S., VAUGHAN-JACKSON, J.D. \& FARID, N.R. (1976). Inappropriate TSH secretion. Paradoxical rise in serum TSH in response to thyroxine therapy. Journal of Clinical Endocrinology and Metabolism, 43, 1360.

KUBICEK, W.G., KARNEGIS, J.N., PATTERSON, R.P., WITSOE, D.A. \& MATTSON, R.H. (1966). Development and evaluation of an impedance cardiac output system. Aerospace Medicine, 37, 1208.
TSH radio-immunoassay tests, but this is unlikely account for the present observations, with the possibete exception of the second peak in Case 4. If thyroxi exerts a dual action of competing stimulatory and inhibitory actions on TSH secretion, then Cases 1 and 2 show mixed effects with a dominant tendency f $\&$ r TSH suppression. Case 3 shows a strong inhibito effect, whereas Cases 4, 5 and 6 show a domina stimulatory effect during the first 2 months of treat ment, which is subsequently modified by dose increase. The curvi-linear pattern of decline in TSH noted in Cases 1 to 3 may reflect an initial dominant inhibitory effect followed by more equal competing influences of stimulation and inhibition as thyroigf dosage is increased. These points are important If euthyroidism is to be judged by titration of the response of pituitary TSH to thyroid hormone admis. istration, as a blurred end-point is common. Perhaßs a better index is required for the definition of euthyroidism.

\section{Acknowledgements}

We are grateful to Dr Maurice Scanlon, Senior Lecturer in Medicine, Welsh National School of Medicine, Heath Hoswital, Cardiff, for advice; and to Miss Julie E. Davies fö secretarial assistance.

LARSEN, P.R., DICK, T.E., MARKOVITZ, B.P., KAPQ̈ M.M. \& GARD, T.G. (1979). Inhibition of intra-piturtagy thyroxine to $3,5,3^{1}$-triiodothyroxine conversion preven the acute suppression of thyrotropin release by thyroxiofe in hypothyroid rats. Journal of Clinical Investigation, 117.

MORGAN, W.D., BIRKS, J.L., SIVYER, A. \& GHOSE, R. $\overrightarrow{\mathrm{B}}$ (1977). An efficient technique for the simultaneous estimtion of GFR and ERPF, involving a single injection and two blood samples. International Journal of Nucleai Medicine and Biology, 4, 79.

RIDGWAY, E.C., KOURIDES, I.A., CHIN, W.W., COOPER, D? \& MALOOF, F. (1979). Augmentation of pituitary TS response to TRH during subphysiological triiodothyro ine therapy in hypothyroidism. Clinical Endocrinology, $\mathbf{1 0}$ (4), 343.

SCANLON, M.F., SMITH, B.R. \& HALL, R. (1978). Thyroid stimulating hormone: neuroregulation and clinicgl applications. Clinical Science and Molecular Medicine, 5 , 1.

SPIRA, O., GROSS, J. \& GORDON, A. (1981). The synthesis ang release of TSH in the thyroidectomized rat. c) The effect of T3 in hypothyroidism of varying duration. Acta Endocring ologica, $97,85$.

WARTOFSKY, L., DIMOND, R.C., NOEL, G.L., FRANTZ, A. $§$ ? \& EARLL, J.M. (1976). Effect of acute increases in serue triiodothyronine on TSH and prolactin responses to TRK and estimates of pituitary stores of TSH and prolactin normal subjects and in patients with primary hypoth yroidism. Journal of Clinical Endocrinology and Metabots ism, 42, 443. 